\title{
Megaloblastic anemia: A common but often neglected cause of pyrexia of unknown origin
}

\author{
Bushra Siddiqui, Divya Rabindranath, Shahbaz Habib Faridii ${ }^{1}$, Azka Anees Khan, \\ Sadaf Haiyat, Rabindranath Eswaran ${ }^{2}$ \\ Departments of Pathology, 'Surgery and 'Medicine, Jawaharlal Nehru Medical College, Aligarh Muslim \\ University, Aligarh, Uttar Pradesh, India
}

Address for Correspondence: Dr. Shahbaz Habib Faridi, Department of Surgery, Jawaharlal Nehru Medical College, Aligarh Muslim University, Aligarh, Uttar Pradesh, India. E-mail: sh

\begin{tabular}{|l|}
\hline Access this article online \\
Website: \\
www.intern-med.com \\
\hline DOI: \\
10.1515/jtim-2015-0005 \\
\hline Quick Response Code: \\
\hline \\
\hline
\end{tabular}

\section{ABSTRACT}

Objective: The objective was to study megaloblastic anemia as a cause of pyrexia of unknown origin (PUO). Materials and Methods: We conducted a study on 15 patients of megaloblastic anemia associated with fever, attending our hospital clinics over a period of 6 months. Results: While 11 patients had symptoms suggesting foci of infection and responded well to intravenous antibiotics, 4 patients had neither any evidence of infection nor responded with empirical broad spectrum antibiotic treatment. They were treated with vitamin B12/folate therapy which led to marked improvement in fever within $48 \mathrm{~h}$. Presenting complaints of the patients and severity/duration of fever along with other epidemiological data were also studied in each case. Conclusion: The present study led us to conclude that megaloblastic anemia forms an important and reversible cause of fever and should be ruled out in all patients presenting with PUO. This knowledge would help the physicians in adequate and timely management of these patients.

Key words: Folate, megaloblastic anemia, pyrexia of unknown origin, vitamin B12

\section{INTRODUCTION}

Megaloblastic anemia is a group of disorders characterized by ineffective hematopoiesis, frequently manifested by peripheral blood cytopenia. They are usually caused by nutritional deficiencies (most common) of either vitamin B12 or folate or both, inherited disorders of DNA synthesis, or following certain drug therapy. ${ }^{[1]}$ Pyrexia in megaloblastic anemia is a well-known and reversible phenomenon. However, its characterization as the sole cause of fever is rare. The differentiation from pyrexia of unknown origin (PUO) in such cases is difficult and often requires exhaustive laboratory investigations.

The aim of this article was to highlight this aspect of megaloblastic anemia and the importance of considering this diagnosis in all cases presenting with PUO.

\section{MATERIALS AND METHODS}

This study was conducted on 15 patients of megaloblastic anemia associated with fever, attending the outpatient department over a period of 6 months (June 2014 to November 2014).

The inclusion criteria for the study were temperature of $100 \mathrm{~F}\left(37.8^{\circ} \mathrm{C}\right)$ or more, hemoglobin level $<10 \mathrm{~g} / \mathrm{dl}$, mean corpuscular volume $(\mathrm{MCV})>100 \mathrm{fL}$, peripheral blood film findings consistent with megaloblastosis (including macrocytosis, hypersegmented neutrophils and pancytopenia in few cases), low serum vitamin B12 and/or folate levels, and bone marrow findings consistent with megaloblastic anemia.

All other causes of fever were excluded by appropriate investigations (complete hemogram, ASO titer, blood film for malarial parasite, Widal test, Brucella agglutination test, Weil-Felix test, dengue serology, leptospira serology, rheumatoid factor, blood culture, liver function test, renal function test, complete urine examination, chest radiograph, ultrasound abdomen and pelvis and others). 


\section{RESULTS}

A total of 64 patients of megaloblastic anemia attended our hospital clinics over the mentioned 6 months period. Only 15 of these satisfied the inclusion criteria and were included in the study.

Majority of the patients were from rural areas (12 out of 15, 80\%). There were 13 females and 2 males. Most of the patients belonged to the age group of 21-40 years and most had duration of illness of around 3 weeks. 12 of the patients were vegetarians while the remaining 3 were occasional nonvegetarians. There was no history of cough, headache, arthralgia, rashes, jaundice or exposure to any patient of tuberculosis in any of the patients.

On examination, all the patients showed moderate to marked pallor. No lymphadenopathy, rashes, icterus or eschar were seen. Five of the patients showed bald, glossy tongue. Two patients had hyperpigmentation of knuckles. Cardiovascular system examination revealed loud S1 heart sound and ejection systolic murmur in the pulmonary area in 8 patients. Abdominal examination revealed mild to moderate splenomegaly in majority of patients (10 out of 15). Respiratory and nervous system examination were normal. Table 1 illustrates the clinical characteristics of all the patients.

Fever and dyspnea were the main presenting symptoms. 12 patients had fever of 100-102 F and 3 had a temperature of $>102 \mathrm{~F}$. Two patients had fever lasting for $<7$ days, $10 \mathrm{had}$ fever from 7 to 20 days and 3 had fever $>21$ days. Other symptoms were easy fatigability ( 8 patients, $53 \%$ ), anorexia and gastritis (5 patients, 33\%) and bleeding tendency in 1 patient (6.7\%). Table 2 demonstrates the hemoglobin levels, MCV values and serum folate/vitamin B12 levels of the patients.

Nine patients $(60 \%)$ had low serum levels of vitamin B12 only, $2(13.3 \%)$ had decreased serum folate levels only; while $4(26.6 \%)$ had combined deficiency of both.

Peripheral blood smear examination revealed anisopoikilocytosis with macrocytosis in most cases. Basophilic stippling and hypersegmented neutrophils were also seen in few. Four cases $(26.6 \%)$ showed pancytopenia. Bone marrow examinations were available in all 15 patients and revealed moderate to severe megaloblastosis.

Initially, all the patients were started on empirical broad spectrum intravenous (IV) antibiotic treatment. Eleven $(73 \%)$ of them responded to this approach and showed a decrease in temperature levels. However, 4 (26.6\%) continued to remain febrile. In these patients, antibiotics

\begin{tabular}{|c|c|c|c|c|}
\hline \multirow{2}{*}{$\begin{array}{l}\text { Parameters } \\
\text { Age (in years) }\end{array}$} & \multicolumn{4}{|c|}{ Number of patients } \\
\hline & & & & \\
\hline $16-20$ & \multicolumn{4}{|c|}{2} \\
\hline $21-40$ & \multicolumn{4}{|c|}{8} \\
\hline $41-60$ & \multicolumn{4}{|c|}{4} \\
\hline$>61$ & \multicolumn{4}{|c|}{1} \\
\hline \multicolumn{5}{|l|}{ Sex } \\
\hline Male & \multicolumn{4}{|c|}{2} \\
\hline Female & \multicolumn{4}{|c|}{13} \\
\hline \multicolumn{5}{|l|}{ Temperature $(\mathrm{F})$} \\
\hline $100-102$ & \multicolumn{4}{|c|}{12} \\
\hline$>102$ & \multicolumn{4}{|c|}{3} \\
\hline \multicolumn{5}{|l|}{ Symptoms } \\
\hline \multirow[t]{3}{*}{ Fever } & \multicolumn{4}{|c|}{15} \\
\hline & Period & $<7$ days & 7-20 days & $>21$ days \\
\hline & $\begin{array}{c}\text { Number of } \\
\text { patients }\end{array}$ & 2 & 10 & 3 \\
\hline Easy fatigability & & & 8 & \\
\hline Breathlessness & & & 8 & \\
\hline Anorexia and gastritis & & & 5 & \\
\hline Bleeding tendency & & & 1 & \\
\hline
\end{tabular}

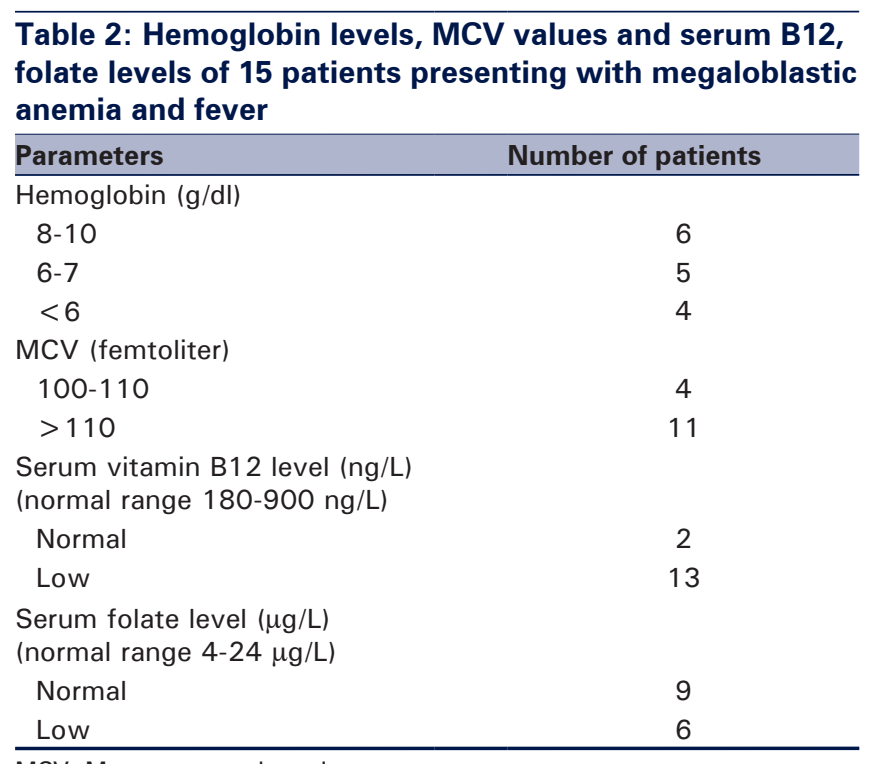

MCV: Mean corpuscular volume

were stopped, and vitamin B12 and folate supplementation was started. All of these 4 patients showed symptomatic improvement within $48 \mathrm{~h}$ along with the improvement in hematological parameters by the $7^{\text {th }}$ day. Patients were subsequently discharged and followed-up after 2 and 4 weeks. Further improvement in hemoglobin, MCV, and other hematological parameters were seen on follow-up.

Table 3 describes the clinical and investigation findings in 4 patients who showed improvement with vitamin B12 and folate administration. Most of these patients were females with low-grade fever lasting for the duration of 


\begin{tabular}{|c|c|}
\hline \multicolumn{2}{|c|}{$\begin{array}{l}\text { Table 3: Clinical and hematological parameters of } 4 \\
\text { patients who showed improvement with vitamin B12 } \\
\text { and folate administration }\end{array}$} \\
\hline Parameters & Number of patients \\
\hline \multicolumn{2}{|l|}{ Age (years) } \\
\hline $21-40$ & 1 \\
\hline $41-60$ & 2 \\
\hline$>61$ & 1 \\
\hline \multicolumn{2}{|l|}{ Sex } \\
\hline Male & 1 \\
\hline Female & 3 \\
\hline \multicolumn{2}{|c|}{ Temperature (F) } \\
\hline $100-102$ & 3 \\
\hline$>102$ & 1 \\
\hline \multicolumn{2}{|c|}{ Duration of fever } \\
\hline$<2$ weeks & 1 \\
\hline$>2$ weeks & 3 \\
\hline \multicolumn{2}{|c|}{ Hemoglobin $(g / d l)$} \\
\hline $6-7$ & 1 \\
\hline$<6$ & 3 \\
\hline \multicolumn{2}{|c|}{ MCV (femtoliter) } \\
\hline$>110$ & 4 \\
\hline \multicolumn{2}{|c|}{$\begin{array}{l}\text { Serum vitamin B12 level (ng/L) } \\
\text { (normal range } 180-900 \mathrm{ng} / \mathrm{L} \text { ) }\end{array}$} \\
\hline Normal & 1 \\
\hline Low & 3 \\
\hline \multicolumn{2}{|c|}{$\begin{array}{l}\text { Serum folate level ( } \mu \mathrm{g} / \mathrm{L} \text { ) (normal } \\
\text { range } 4-24 \mu \mathrm{g} / \mathrm{L} \text { ) }\end{array}$} \\
\hline Normal & 0 \\
\hline Low & 4 \\
\hline
\end{tabular}

MCV: Mean corpuscular volume

$>2$ weeks. Majority had severe anemia with hemoglobin $<6$ $\mathrm{g} / \mathrm{dl}$. All had MCV >110 femtoliter. Three of the patients had combined deficiency of B12 and folate while 1 had isolated folate deficiency.

\section{DISCUSSION}

As observed in our study, infection continues to be the most common cause of fever in patients of megaloblastic anemia. This is evidenced by the fact that $73 \%$ of our patients showed improvement on administration of broad spectrum IV antibiotics. This was despite the fact that no obvious focus of infection could be found in them, even after extensive investigations. It has been suggested that patients of megaloblastic anemia are more susceptible to infection due to impaired intracellular killing of ingested bacteria by the neutrophils and macrophages. ${ }^{[2]}$ The metabolic activation is reduced by $35-36 \%$ in the leukocytes that are deficient in B12 (but not so with folate deficiency). Hence, bacterial killing is reduced and abnormal; and it is reverted after specific therapy. ${ }^{[3]}$

However, 4 of our patients (26.6\%) showed no improvement with antibiotics but showed marked improvement within $48 \mathrm{~h}$ on administration of vitamin B12 and folate. This shows that though it is rare to find megaloblastic anemia as the sole cause of fever, it still remains an important and often overlooked cause of the same. Such cases are often treated as cases of PUO, and precious time and money is wasted on their management. As per the modified Petersdorf criteria, FUO is defined as:

1. A temperature exceeding $38.3^{\circ} \mathrm{C}$;

2. Duration of the fever of more than 3 weeks; and

3. Evaluation of three outpatient visits or 3 days in hospital. ${ }^{[4]}$

On the review of literature for causes of PUO, we found that megaloblastic anemia is not included in the list yet. ${ }^{[5]}$

The association of fever with megaloblastic anemia has been well documented in the past. ${ }^{[-10]}$ We found in our study that most of the patients had low-grade fever with temperature $<100 \mathrm{~F}$. The temperature was $>102 \mathrm{~F}$ in only 3 of the 15 patients (20\%). Furthermore, it was observed that most of the patients who presented with megaloblastic anemia being the sole cause of fever; had a longer duration of disease, more severe anemia and higher values of MCV. Such findings have also been found in earlier studies. ${ }^{[8]}$

The exact cause of fever in megaloblastic anemia remains unknown. Various hypotheses have been proposed, but none have been proved yet. It has been suggested that since megaloblastic anemia is a panmyelosis, characterized by hypercellular marrow and ineffective hematopoiesis, premature destruction of hematopoietic precursors could possibly release intracellular substances which might function as systemic pyrogens. ${ }^{[1]}$ Alternatively, studies have proposed that defective oxygenation at the thermoregulatory center of the hypothalamus might be the explanation for pyrexia. However, lack of correlation between neurological manifestation and pyrexia in megaloblastic disease negates this theory. ${ }^{[8]}$ To confound matters even further, few studies have shown that a rise in temperature might cause depletion of folate stores, both in red blood cells and serum, leading to disturbances in folate metabolism. ${ }^{[12]}$ Hence, whether pyrexia is a cause or effect of folate deficiency remains to be fully understood.

Although the reason behind it remains unclear, the association of fever with megaloblastic anemia remains a well-documented phenomenon. Further studies on bone marrow microenvironment and role of cytokine signaling in these cases would help in discovering the cause in the future.

\section{CONCLUSION}

We conclude that though infection remains to be the most common cause of pyrexia in patients of 
megaloblastic anemia, few cases also show a causal relationship between the two. Hence, measurement of B12 and folate levels should be advised in all patients presenting with fever without any obvious cause. The correct identification of B12/folate deficiency being the cause of fever (after all other causes have been ruled out), would help in adequate and timely management of the patient and avoid unnecessary use of antibiotics.

\section{REFERENCES}

1. Aslinia F, Mazza JJ, Yale SH. Megaloblastic anemia and other causes of macrocytosis. Clin Med Res.2006;4:236-41.

2. Gomber S, Kela K, Dhingra N. Clinico-hematological profile of megaloblastic anemia. Indian Pediatr 1998;35:55-8.

3. Kaplan SS, Basford RE. Effect of vitamin B12 and folic acid deficiencies on neutrophil function. Blood 1976;47:801-5.

4. Kucukardali Y, Oncul O, Cavuslu S, Danaci M, Calangu S, Erdem H, et al. The spectrum of diseases causing fever of unknown origin in Turkey: A multicenter study. Int J Infect Dis 2008;12:71-9.
5. Gelfand JA, Callahan MV. Fever of unknown origin. Harrison's Principles of Internal Medicine. $18^{\text {th }}$ ed. New York: McGraw-Hill; 2012. p. 158-64.

6. Tahlan A, Bansal C, Palta A, Chauhan S. Spectrum and analysis of bone marrow findings in anemic cases. Indian J Med Sci 2008;62:336-9.

7. Khanduri U, Sharma A. Megaloblastic anaemia: Prevalence and causative factors. Natl Med J India 2007;20:172-5.

8. McKee LC Jr. Fever in megaloblastic anemia. South Med J 1979;72:1423-4, 1428.

9. Negi RC, Kumar J, Kumar V, Singh K, Bharti V, Gupta D, et al. Vitamin B12 deficiency presenting as pyrexia. J Assoc Physicians India 2011;59:379-80.

10. Singanayagam A, Gange N, Singanayagam A, Jones H. Folate deficiency presenting as pyrexia: A case report. Cases J 2008 26;1:275.

11. Manuel K, Padhi S, G'boy Varghese R. Pyrexia in a patient with megaloblastic anemia: A case report and literature review. Iran J Med Sci 2013;38 (2 Suppl):198-201.

12. Osifo BO, Lukanmbi FA, Familusi JB. Increase of body temperature and folic acid metabolism. Acta Vitaminol Enzymol 1981;3:177-81.

How to cite this article: Siddiqui $B$, et al. Megaloblastic anemia: A common but often neglected cause of pyrexia of unknown origin. J Transl Intern Med 2015;3:64-67

Source of Support: NIL, Conflict of Interest: NIL 